\title{
Incontinência urinária de esforço em mulheres no menacme: tratamento com exercicios do assoalho pélvico associados ao biofeedback eletromiográfico
}

\author{
Stress urinary incontinence in women in reproductive age: treatment with sEMG-assisted \\ biofeedback
}

Autora: Mariana Tirolli Rett

Orientador: Prof. Dr. José Antonio Simões

Co-orientadora: Prof. Dra. Viviane Herrmann

Dissertação de Mestrado apresentada à Pós-graduação do Departamento de Tocoginecologia da Faculdade de Ciências Médicas (FCM) da Universidade Estadual de Campinas (UNICAMP), em 25 de novembro de 2004.

Objetivo: avaliar o tratamento fisioterápico da incontinência urinária de esforço (IUE) feminina com exercícios do assoalho pélvico associados ao biofeedback eletromiográfico. Sujeitos e Métodos: ensaio clínico não controlado de 26 mulheres no menacme. Foram excluidas aquelas com diagnóstico urodinâmico de deficiência esfincteriana intrínseca da uretra e hiperatividade idiopática do detrusor, distopias grau III e cirurgias prévias para IUE. Todas preencheram um diário miccional, responderam a um questionário de qualidade de vida (King's Health Questionnaire) e a outro para elaboração de um indice de perda urinária. Foram submetidas ao teste do absorvente (pad test) de uma hora e à avaliação da força muscular do assoalho pélvico pelo toque vaginal, pelo perineômetro (Peritron ${ }^{\mathrm{TM}}$ ) e pela eletromiografia de superficie (Myotrac 3G ${ }^{\mathrm{TM}}$ ). O protocolo consistia em 12 sessões individuais e os exercícios foram realizados em decúbito dorsal, nas posições sentada e ortostática. Resultados: As perdas urinárias diminuíram $(\mathrm{p}<0,0001)$ e o mesmo foi observado em relação à noctúria $(p=0,0012)$ e ao número de absorventes utilizados $(\mathrm{p}=0,0014)$. A cura objetiva pelo pad test foi encontrada em 20 (76,9\%) mulheres. Houve um aumento na força de contração do assoalho pélvico, tanto pelo toque vaginal quanto pelo perineômetro $(\mathrm{p}<0,0001)$. A eletromiografia de superficie aumentou ao longo do tratamento, principalmente na primeira metade $(\mathrm{p}<0,0001)$. O índice de perda urinária diminuiu e observou-se melhora da qualidade de vida em praticamente todos os parâmetros avaliados. Conclusão: este tratamento fisioterápico pode ser uma alternativa eficaz na abordagem conservadora da IUE em mulheres no menacme.

PALAVRAS-CHAVE: Incontinência urinária de esforço; Estudo urodinâmico; Qualidade de vida; Eletromiografia

Resumo de Tese

\section{Comparação entre Acidform gel e metronidazol gel para o tratamento da vaginose bacteriana: en- saio clínico piloto fase 2}

\author{
Comparison between Acidform gel and metronidazole gel for the treatment of bacterial \\ vaginosis: a phase 2 pilot clinical trial
}

Autor: Rodrigo Pauperio Soares de Camargo

Orientador: Prof. Dr. José Antonio Simões

Tese de Doutorado apresentada à Pós-Graduação do Departamento de Tocoginecologia da Faculdade de Ciências Médicas (FCM) da Universidade Estadual de Campinas (UNICAMP), em 26 de novembro de 2004.

Objetivo: comparar a eficácia e a segurança do Acidform gel intravaginal com o metronidazol gel para o tratamento da vaginose bacteriana (VB). Metodologia: Após um diagnóstico de VB confirmado pelos critérios de Amsel e de Nugent, foram incluidas 30 mulheres neste ensaio clínico piloto, duplo-cego e randomizado. As mulheres foram randomizadas para receberem $5 \mathrm{~g}$ de Acidform gel $(\mathrm{n}=13)$ ou de metronidazol gel ( $\mathrm{n}=17$ ) intravaginal, uma vez ao dia por 5 dias consecutivos. As participantes foram avaliadas em duas consultas de seguimento (7-12 dias e 2835 dias após o tratamento). O sucesso terapêutico foi definido como a presença de menos do que três dos critérios de Amsel. Se três ou mais critérios estavam presentes na primeira ou na segunda visita de seguimento, a mulher era considerada como falha de tratamento, tratada com metronidazol oral e retirada do estudo. Os escores de Nugent foram realizados em cada uma das consultas, porém não foram utilizados como critérios de cura para a VB. As variáveis estudadas foram: cura objetiva, cura subjetiva, aceitabilidade geral, irritação vulvovaginal, cultura positiva para Candida sp. e eventos adversos (EA) após o uso dos produtos. Resultados: após uma semana do final do tratamento o índice de cura objetiva do Acidform gel foi de $23 \%$ e do metronidazol gel foi de $88 \%$ ( $p<0,001)$. Após um mês do tratamento o indice de cura objetiva do Acidform foi de $8 \%$ e do metronidazol foi de $53 \%$ ( $p<0,01)$. A cura subjetiva foi referida por todas as mulheres que relataram cura parcial ou total após o tratamento e, portanto, não se correlacionou bem com a cura objetiva. Durante o uso dos produtos, $31 \%$ das mulheres tratadas com 
Acidform e 6\% das tratadas com metronidazol perceberam alguma irritação vulvovaginal $(\mathrm{p}=0,138)$. A cultura para Candida sp. positiva foi semelhante entre os grupos, após o tratamento da VB. Conclusão: o Acidform gel intravaginal teve um indice de cura para VB significativamente inferior ao metronidazol gel tanto uma semana quanto um mês após o tratamento e mostrou-se ineficaz como tratamento alternativo para a VB. Entretanto, o Acidform gel intravaginal por cinco dias consecutivos mostrou-se seguro e com boa aceitabilidade geral.

PALAVRAS-CHAVE: Vaginose bacteriana; Microbicidas

Resumo de Tese

\title{
Prevalência da colonização pelo estreptococo do grupo $\mathrm{B}$ em gestantes atendidas no ambulatório de pré-natal do Hospital Universitário da Universidade Federal de Santa Catarina
}

\author{
Prevalence of group B streptococcus in pregnant women from the prenatal care center \\ of the "Hospital Universitário da Universidade Federal de Santa Catarina" (University \\ Hospital of the Federal University of Santa Catarina, Brazil)
}

Aluna: Adriane Pogere

Orientador: Prof. Dr. Paulo Fontoura Freitas

Dissertação apresentada ao curso de Pós-Graduação em Ciências Médicas da Universidade Federal de Santa Catarina para obtenção do título de Mestre, em 13 de fevereiro de 2004

Objetivo: determinar a prevalência de estreptococo do grupo B (EGB) em gestantes no terceiro trimestre da gravidez e explorar os fatores potencialmente associados à colonização em nosso meio. Métodos: uma amostra de 273 gestantes no terceiro trimestre da gravidez, provenientes do ambulatório de pré-natal do Hospital Universitário da Universidade Federal de Santa Catarina foi investigada. Culturas de amostra vaginal e anorretal foram obtidas e inoculadas em meio seletivo de Todd-Hewitt suplementado com $10 \mathrm{mg} / \mathrm{ml}$ de colistina e $15 \mathrm{mg} / \mathrm{ml}$ de ácido nalidíxico e posteriormente subcultivadas em ágar sangue de carneiro desfibrinado. Resultados: a prevalência de colonização pelo EGB foi de 21,6\%, sendo que 9,9\% das gestantes tiveram positividade em ambos os sítios; $6,95 \%$ foram positivas somente no sítio vaginal e $4,75 \%$ da amostra tiveram positividade apenas no sítio anal. Fatores detectados como potencialmente associados à colonização pelo EGB foram: primíparas com mais de 30 anos e mulheres com mais de um parceiro sexual e freqüência de atividade sexual aumentada $(p<0,05)$. Não foi encontrada diferença na prevalência de acordo com história de doença sexualmente transmissivel, aborto espontâneo pregresso e tabagismo. Conclusão: confirma-se a necessidade de cultura rotineira para EGB em ambos os sitios (vaginal e anal) de todas as gestantes no terceiro trimestre de gestação.

PALAVRAS-CHAVE: Estreptococo do grupo B; Gravidez normal; Gravidez: infecções

\section{Lesões intra-epiteliais vulvares em pacientes infectadas pelo HIV}

\section{Intraepithelial vulvar lesions in HIV-infected patients}

Autor: Ricardo José de Oliveira e Silva

Tese apresentada ao Centro de Ciências Biológicas e de Saúde da Universidade Federal do Estado do Rio de Janeiro - UNIRIO, como parte dos requisitos necessários ao Concurso Público de Títulos e Provas para Livre Docência, em agosto de 2004 .

Objetivos: avaliar a prevalência de lesões escamosas intra-epiteliais vulvares em pacientes infectadas pelo HIV atendidas em rede pública na Cidade do Rio de Janeiro e estudar os fatores associados a essas lesões. Material e Método: 374 pacientes infectadas pelo HIV e atendidas em serviços públicos na Cidade do Rio de Janeiro foram submetidas a exame ginecológico, colheita de citologia e exame colposcópico do colo uterino e vulva. A associação do diagnóstico de lesão intra-epitelial da vulva foi analisada de acordo com os resultados de variáveis clínicas (idade e presença de lesões cervicais), laboratoriais (contagem de CD4) e comportamentais (número de parceiros e hábito de fumar). Resultados: a prevalência de lesões intra-epiteliais vulvares foi de $40 \%$. $\mathrm{Na}$ análise multivariada mostraram-se significativas: contagem de CD4 abaixo de 500 céls $/ \mathrm{mm}^{3} \mathrm{OR}=2,69$ [IC 95\% 1,61 - 4,52], a colposcopia anormal OR $=1,64$ [IC $95 \% 1,01-2,67$ ] e idade abaixo de 26 anos OR = 1,98 [IC $95 \% 1,18-3,30]$. Na análise do subgrupo de pacientes que apresentaram lesões simultâneas no colo e na vulva, mostraram-se significativas no modelo final apenas a idade abaixo de 26 anos OR = 3,30 [IC 95\% 1,65 - 6,59] e 